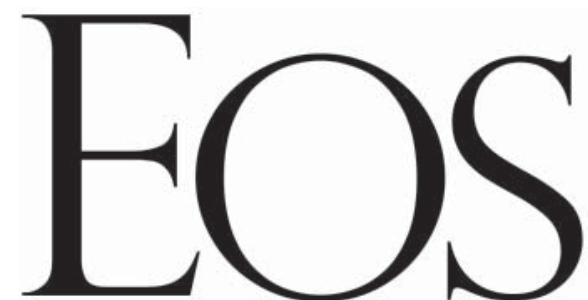

EOS, TRANSACTIONS, AMERICAN GEOPHYSICAL UNION
VOLUME 88 NUMBER 10

6 MARCH 2007

PAGES 117-128

\section{A Very Active Sprite-Producing Storm Observed Over Argentina}

\section{PAGES 117, 119} more than 400 middle-atmospheric optical discharges were observed above one large thunderstorm system over northeastern Argentina. These transient luminous events (TLEs) were imaged during the Southern Brazil Sprite Campaign, the first campaign to focus on TLEs over southern Brazil, northeastern Argentina, and Uruguay. All of the TLEs were imaged from the Brazilian Southern Space Observatory (SSO) near Santa Maria, which is nearly in the center of the southernmost Brazilian state of Rio Grande do Sul. Although the fields of view of the imaging cameras were too narrow to view the entire storm, the more than 400 confirmed TLEs imaged indicate that this storm ranks as the third most active TLE producer ever reported. Hence, storms in this region of South America might be some of the leading TLE generators on Earth.

The Southern Brazil Sprite Campaign is a joint project between the United States (University of Washington, Utah State University, and Duke University) and Brazil (National Institute of Space Research; INPE). The primary goal of the campaign is to measure the in situ electric field above sprite-parent lightning using sensors flown on zero-pressure stratospheric balloons. Unfortunately, for the two nights that TLEs were imaged during the campaign window of February-March 2006, the storms were well beyond the range of the predicted balloon flight path. Hence, no in situ measurements were attempted on these nights.

In this article, we present a brief overview of the video data of TLEs occurring over Argentina and Brazil on 22-23 February, along with coincident lightning location data from the World Wide Lightning Location Network (WWLLN; see http://webflash.ess.washington.edu/) together with extremely low to

By J. N. Thomas, M. J. Taylor, D. Pautet, M. Bailey, N. N. Solorzano, R. H. HolzWORTH, M. P.McCaRTHY, M. Kokorowski, F. SaO SabBas, O. Pinto JR, S. A. Cummer, N. Jaugey, J. Li, AND N. J. Schuch
During the night of 22-23 February 2006 very low frequency (ELF/VLF) electric and magnetic field data recorded at the observatory. We are currently analyzing these data further and plan to publish in-depth, detailed studies of these TLEs and their parent thunderstorms in the near future. This region of South America is likely one of the most active global locations for intense lightning and TLE production, and these investigations will be a major step toward a global characterization of the electrical coupling between the troposphere and the middle and upper atmosphere.

\section{The TLE Family}

Sprites, halos, jets, and elves are members of a family of TLEs that illuminate the stratosphere and mesosphere above thunderstorms, usually between 20 and 95 kilometers in altitude. In addition to their intrinsic physi- cal interest, there are numerous broader implications for studying sprites and other TLE events. In particular, they may be a significant driver or discharging mechanism for the global electrical circuit, the 200-kilovolt potential between the Earth and the ionosphere that is thought to be maintained by thunderstorms and lightning. TLEs may also produce nitrous oxides $\left(\mathrm{NO}_{x}\right)$, an important component gas for ozone chemistry, in the middle atmosphere.

Furthermore, these high-altitude discharges transfer energy from the troposphere to the middle and upper atmosphere, and might be a significant driver of electron density changes in the lower ionosphere. Thus, TLEs may adversely affect radio communications systems, GPS, and aircraft. Finally, terrestrial gamma-ray flashes (TGFs), of more than 1 mega-electronvolt in energy, have been detected by satellites orbiting Earth, such as the Reuven Ramaty High Energy Solar Spectroscopic Imager (RHESSI) spacecraft [Smith et al., 2005]. TGF production has been correlated with thunderstorms and might be related to TLEs. Determining the exact source of these energetic photons may well lead to some fundamental new understandings of thunderstorms.

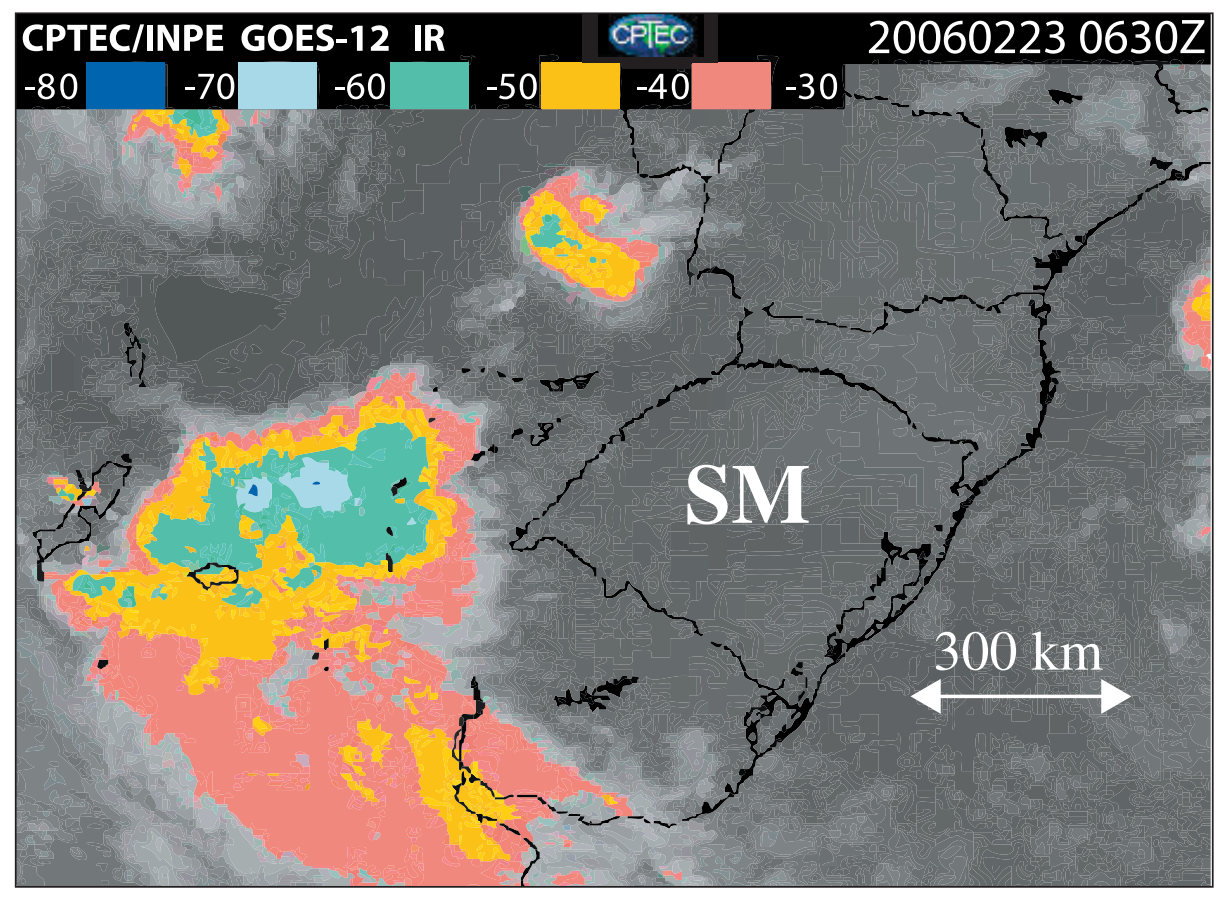

Fig. 1. GOES-12 infrared image of a sprite-producing thunderstorm system to the west and southwest of the Brazilian Southern Space Observatory near Santa Maria (SM). 


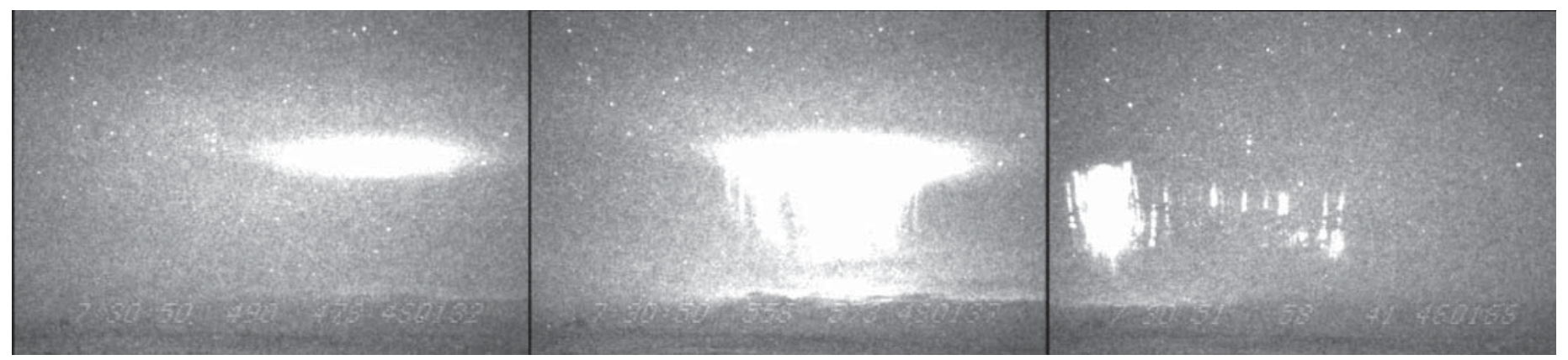

Fig. 2. Halos and sprites over Argentina that occurred within about 0.60 seconds (from left to right) observed from the Brazilian Southern Space Observatory on 23 February 2006. The maximum altitude of these optical emissions is 80-90 kilometers.

Most of the TLEs imaged over Argentina were sprites, which are optical discharges that last up to tens of milliseconds that occur between 40 and 90 kilometers in altitude. These high-altitude discharges were first imaged by chance by the late Jack Winckler's group at the University of Minnesota [Franz et al., 1990]. Sprites have since been correlated almost exclusively with positive cloudto-ground lightning (+CG) strokes with large charge moment changes (defined as the total charge removed times the initial charge height). They usually occur during large thunderstorms, known as mesoscale convective systems (MCSs), which have large cloud areas capable of maintaining thousands of coulombs of charge.

To date, the majority of sprites have been observed over MCSs that develop during the spring and summer months over the High Plains area of the U.S. Great Plains. However, extremely low frequency ( 3 hertz to 3 kilohertz) magnetic field resonances of the Earth-ionosphere waveguide, which are driven by large charge moment change lightning, suggest that this region of South America may be one of the most active areas for sprite production globally [Sato and Fukunishi, 2003].

\section{The February 2006 Thunderstorms}

During the late morning hours (local time) of 22 February 2006, a large thunderstorm system formed over the Pampas region of Argentina, east of Buenos Aires. This storm system further developed and strengthened throughout the day while moving northward. By 0230 UT on 23 February (22 February, 11:30 P.M. local time), when the first sprites were observed from the Brazilian Southern Space Observatory, the storm encompassed an area of about 300,000 square kilometers (based on Geostationary Operational Environmental Satellite (GOES)-12 infrared images of cloud top temperatures below $40^{\circ} \mathrm{C}$ ) and was producing significant amounts of lightning as detected by the WWLLN and the Brazilian Lightning Detection network. Between 0230 and 0830 UT, 446 TLEs (mostly sprites and some halos or elves) were observed.

Figure 1 is a GOES 12 satellite infrared image of the sprite-producing thunderstorm at 0630 UT located about 500-800 kilo- meters to the west and southwest of the observatory near Santa Maria (indicated by the letters SM). Note that the $-40^{\circ} \mathrm{C}$ cloud shield had a maximum area of about 550,000 square kilometers, which is larger than most sprite-producing thunderstorms over the U.S. High Plains that typically have a cloud shield of less than about 450,000 square kilometers [Lyons et al., 2006]. In fact, large thunderstorm systems are common in this region of South America during the spring and summer months, which further suggests that this is an active region of sprite production and a major driver for our experimental program. However, the details of how these South American sprite-producing storms compare and contrast with sprite-producing storms over the U.S. High Plains is not yet known and is the topic of future analysis.

Figure 2 shows halos and sprites, imaged from a single camera, that occurred within about 0.60 seconds (from left to right) starting at 0730:50.490 UT correlated with WWLLN-located lightning events. The left frame of Figure 2 is a disc-like halo at a range of about 585 kilometers with a diameter of about 66 kilometers. This halo is correlated with +CG lightning with an impulse charge moment change ( $\left.i \Delta M_{q}\right)$ of 254 coulomb kilometers, where $i \Delta M_{q}$ is the charge moment change in the first 2 milliseconds of the stroke calculated from ground-based ELF/VLF measurements.

Recorded 66 milliseconds after the left frame, the middle frame of Figure 2 shows a sprite accompanied by a halo at a range of about 578 kilometers with a maximum width of about 82 kilometers correlated with a 368 coulomb kilometer $i \Delta M_{q}+\mathrm{CG}$ lightning. The right frame, recorded 501 milliseconds later, shows dancing sprites along with a larger, carrot-shaped sprite at a range of about 611 kilometers correlated with 157 and 194 coulomb kilometer $i \Delta M_{q}+\mathrm{CG}$ lightning.

The width of this collection of luminous structures in the right frame is approximately 90 kilometers. Since the carrot sprite shown in the right frame occurred more than 50 milliseconds after the two parent +CG lightning strokes, the impulsive charge moment changes do not necessarily indicate the total charge moment changes. Indeed, very large continuing currents, which are low-level currents that follow return strokes, were measured by the ELF/VLF sensor following these strokes. For example, the 194 coulomb kilometer $i \Delta M_{q}+\mathrm{CG}$ lightning had a continuing current amplitude of about 20 kiloampere kilometers that lasted for about 200 milliseconds. Thus, the total charge moment change was several thousands of coulomb kilometers. Unfortunately, with a video rate of 30 frames per second, the timing uncertainty is too great for the total charge moment change associated with this long-delayed sprite to be determined precisely. Nonetheless, it is likely that a large fraction of the charge transfer responsible for generating the carrot sprite was provided by the long-continuing currents instead of just the return strokes.

During this campaign, on 3-4 March 2006, more than 100 TLEs from a second storm were imaged. The storm was to the northwest of Santa Maria, over parts of Brazil, Argentina, and Paraguay, and had a maximum $-40^{\circ} \mathrm{C}$ cloud shield of about 420,000 square kilometers. These data will be analyzed in future works.

These observations are not the first time that sprites were imaged over this region of South America. The first imaging of sprites from the space shuttle during the early 1990s showed that they were occurring over Argentina [Boeck et al., 1995; Lyons and Williams, 1993], and Blanc et al. [2004] reported observing five sprites over this region from the International Space Station during October 2002 .

\section{Questions to Be Addressed}

Our data analysis is still in progress, but these preliminary findings suggest that further observational campaigns in Argentina, southern Brazil, Paraguay, and Uruguay are most warranted. Some specific questions that we hope to address are the following:

1. What were the meteorological conditions that gave rise to the two Argentine TLEproducing thunderstorms, and how often do they occur? How do these conditions compare with TLE-producing storms observed over the U.S. High Plains and elsewhere?

2. How do the dynamical cloud top temperatures and cloud areas compare with the TLE production rate and locations during the two Argentine storms? How do these parameters compare with TLE-producing storms over the U.S. High Plains and elsewhere? 
3. What is the parent-lightning charge moment change needed to drive sprites during these Argentine storms? How does this compare with the charge moment changes measured over the U.S. High Plains and elsewhere? Are there some sprites that can be driven by relatively low charge moment changes, which are too small to cause breakdown using only the quasi-electrostatic field model?

4. Does the morphology of TLEs differ with meteorological conditions and/or charge moment changes?

Addressing these questions will help lead to a new understanding of the lightning- and TLE-driven coupling between the upper and lower atmosphere in all regions of the world, not just the well-studied U.S. High Plains.

\section{Acknowledgments}

This work was supported by the U.S. National Science Foundation under grants ATM-0091825 and ATM-0355190 to the University of Washington, and by the Brazilian government FAPESP projects 02/01329-1 and 04/12350-7 to the Brazilian National Institute for Space Research (INPE). The authors thank students and staff at the Space Science Laboratory of the Federal University of Santa Maria for their assistance throughout the campaign.

\section{References}

Blanc, E., T. Farges, R. Roche, D. Brebion, T. Hua, A. Labarthe, and V. Melnikov (2004), Nadir observations of sprites from the International Space Station, J. Geophys. Res., 109, A02306, doi:10.1029/ 2003JA009972.

Boeck, W. L. O. H.Vaughan Jr. R. J. Blakeslee, B.Vonnegut, M. Brook, and J. McKune (1995), Observations of lightning in the stratosphere, J. Geophys. Res. 100(D1), 1465-1475.

Franz, R. C., R. J. Nemzek, and J. R.Winckler (1990), Television image of a large electrical discharge above a thunderstorm system, Science, 249, 48-51.

Lyons,W.A., and E. R.Williams (1993), Preliminary investigations of the phenomenology of cloud-tostratosphere lightning discharges, paper presented at the Conference on Atmospheric Electricity, Am Meteorol.Soc St. Louis, Mo., 4-8 Oct.

Lyons, W. A., L. Andersen, T. E. Nelson, and G. R. Huffines (2006), Characteristics of sprite producing electrical storms in the steps 2000 domain, paper presented at the Second Conference on Meteorological Applications of Lightning Data, Am. Meteorol.Soc., Atlanta, Ga., 30 Jan. to 2 Feb.

Sato, M., and H. Fukunishi (2003), Global sprite occurrence locations and rates derived from trian- gulation of transient Schumann resonance events, Geophys. Res. Lett., 30(16), 1859, doi:10.1029/ $2003 \mathrm{GL} 017291$

Smith, D. M., L. I. Lopez, R. P. Lin, and C. P.BarringtonLeigh (2005), Terrestrial gamma-ray flashes observed up to $20 \mathrm{MeV}$,Science, 307, 1085-1088.

\section{Author Information}

Jeremy N. Thomas, Department of Earth and Space Sciences, University of Washington, Seattle; E-mail: jnt@u.washington.edu; Michael J.Taylor, Dominique Pautet, and Matthew Bailey, Center for Atmospheric and Space Sciences and Physics Department, Utah State University, Logan; Natalia N. Solorzano, Physics Department, Digipen Institute of Technology, Redmond, Wash.; Robert H. Holzworth, Michael P.McCarthy, and Michael Kokorowski, Department of Earth and Space Sciences, University of Washington, Seattle; Fernanda Sao Sabbas and Osmar Pinto Jr., National Institute of Space Research (INPE), Sao Jose dos Campos, Brazil; Steven A. Cummer, Nicolas Jaugey, and Jingbo Li, Department of Electrical and Computer Engineer ing, Duke University, Durham, N. C.; and Nelson Jorge Schuch, Brazilian Southern Space Observatory, Southern Regional Space Research Center (CRSPE/INPE), Santa Maria, Brazil.

\section{Sea Level Rise in Tampa Bay}

\section{PAGES 117-118}

Understanding relative sea level (RSL) rise during periods of rapid climatic change is critical for evaluating modern sea level rise given the vulnerability of Antarctic ice shelves to collapse [Hodgson et al., 2006], the retreat of the world's glaciers [Oerlemans, 2005], and mass balance trends of the Greenland ice sheet [Rignot and Kanagaratnam, 2006]. The first-order pattern of global sea level rise following the Last Glacial Maximum (LGM, 21,000 years ago) is well established from coral [Fairbanks, 1989], continental shelf [Hanebuth et al., 2000], and other records [Pirazzoli, 2000] and has been integrated into a global ICE-5G model of glacio-isostatic adjustment (GIA) [Peltier, 2004]. However, uncertainty introduced by paleo water depth of sea level indicators, radiocarbon chronology (i.e., reservoir corrections for marine shell dates), postglacial isostatic adjustment, and other processes affecting vertical position of former shorelines produces scatter in RSL curves, limiting our knowledge of sea level rise during periods of rapid glacial decay.

One example of this limitation is the Gulf of Mexico/Florida region where, despite decades of study, RSL curves produce two

By T. Cronin, N. T. Edgar, G. Brooks, D. Hastings, R. LARSON, A. Hine, S. LOCKER, B. SuTHARD, B. FLOWER, D. HOLLANDER, J.WEHMILLER, D.WILLARD, AND S. SMITH conflicting patterns: those showing progressive submergence with a decelerating rate during the past 5000 years [Scholl et al., 1969] and those showing high sea level during the middle of the Holocene [Blum et al., 2001; Balsillie and Donoghue, 2004], where the Holocene represents a geologic epoch that extends from about 10,000 years ago to present times. This discrepancy is emblematic of the uncertainty surrounding Holocene sea level and ice volume history in general.

Tampa Bay is a shallow ( $\sim$ meter depth) estuary formed by dissolution of the Miocene Arcadia Formation [Hine et al., in press] and deposition of Quaternary sediments in sinkholes and karst depressions during glacio-eustatic sea level cycles. The Tampa Bay Study (http://gulfsci.usgs.gov/ tampabay/index.html), a collaborative project-between the U.S. Geological Survey (USGS), and the University of South Florida and Eckerd College, both in St. Petersburgis investigating the sea level, climatic, and environmental history of Tampa Bay (Figure 1). Here we report on the sedimentary record of early Holocene sea level rise and its relationship to regional and global sea level and polar ice volume.

\section{Quaternary Stratigraphy and Chronology}

Tampa Bay stratigraphy features alternating episodes of estuarine-marine and nonmarine sedimentation during periods of relatively high (interglacial) and low (glacial) sea level.
An 11.28-meter piston core (MD02-2579) recovered by the R/V Marion Dufresne in July 2002 from 9.14 meters of water in a depression in the central part of Tampa Bay (Figure 1) contained three stratigraphic units characterized by distinct lithology and microfaunas. The lowermost unit 1 (11.2-7.2 meter core depth) consists of shelly sands and yielded radiocarbon ages from greater than 43,000 years ago. Amino acid racemization ages on mollusks, interglacial pollen assemblages, and marine ostracodes suggest it represents the last interglacial period, termed marine oxygen isotope stage 5 . Unit 2 (7.2-2.9 meters) consists of organic and calcareous muds containing nonmarine ostracodes that were deposited in lakes, ponds, and wetlands between the LGM and the end of the Younger Dryas cooling episode ( 11,500 years ago) (D. Willard et al., Deglacial climate variability from central Florida, USA, submitted to Palaeogeography, Palaeoclimatology, Palaeoecology, 2006, hereinafter referred to as D. Willard et al., submitted manuscript, 2006). Unit 3 (2.9-0 meters) consists of marine sandy muds, and represents late Holocene sediments deposited during the past approximately 3500 years.

Unit 2 pinches out laterally from the karst basin in central Tampa Bay, resulting in a 7500-year hiatus between units 2 and 3 due to erosion or nondeposition of lake sediment prior to Holocene sea level rise. However, cores from the nearby Hillsborough Bay region (VC-75, VC-77, VC-78) recovered a conformable sequence of lacustrine and estuarine sediments continuously deposited in a separate karst-like basin, which allow us to pinpoint the age and elevation of early Holo- 